\section{D) Check for updates}

Cite this: Mater. Adv., 2021, 2, 2750

Received 15th December 2020, Accepted 21st March 2021

DOI: 10.1039/d0ma00984a

rsc.li/materials-advances

\title{
PET waste as organic linker source for the sustainable preparation of MOF-derived methane dry reforming catalysts $\dagger$
}

\author{
Leila Karam, ${ }^{\text {ab }}$ Arianna Miglio, $\ddagger^{c}$ Stefania Specchia, (D) ${ }^{c}$ Nissrine El Hassan, (D) a \\ Pascale Massiani ${ }^{\mathrm{b}}$ and Julien Reboul (D) *b
}

\begin{abstract}
A catalyst made of $\mathrm{Ni}^{0}$ nanoparticles highly dispersed on a lamellar alumina support was prepared by an environmentally-friendly route. The latter involved the synthesis of an aluminum-containing metalorganic framework (MOF) MIL-53(Al) in which the linkers were derived from the depolymerization of polyethylene terephthalate (PET) originating from plastic wastes. After demonstrating the purity and structure integrity of the PET-derived MIL-53(Al), this MOF was impregnated with nickel nitrate salt and then calcined to form a lamellar $\mathrm{Ni}-\mathrm{Al}_{2} \mathrm{O}_{3}$ mixed metal oxide with a high surface area $\left(\mathrm{S}_{\mathrm{BET}}=1276 \mathrm{~m}^{2} \mathrm{~g}^{-1}\right.$, $\mathrm{N}_{2}$ sorption). This mixed oxide consisted of nickel aluminate nanodomains dispersed within amorphous alumina, as revealed by PXRD and TPR analyses. Subsequent reduction under $\mathrm{H}_{2}$ resulted in the formation of well-dispersed $5 \mathrm{~nm} \mathrm{Ni}{ }^{0}$ nanoparticles homogeneously occluded within the interlamellar porosity of the $\gamma$-alumina matrix, as attested by electron microscopy. This waste-derived catalyst displayed catalytic performances in the reaction of dry reforming of methane (DRM) as good as its counterpart made from a MOF obtained from commercial benzene-1,4-dicarboxylic acid (BDC). Thus, under similar steady state conditions, at $650{ }^{\circ} \mathrm{C}$ and 1 bar, the PET-derived catalyst led to $\mathrm{CH}_{4}$ and $\mathrm{CO}_{2}$ conversions as high as those on the BDC-derived catalyst, and its catalytic stability and selectivity towards DRM were excellent as well (no loss of activity after $13 \mathrm{~h}$ and $\mathrm{H}_{2}$ : $\mathrm{CO}$ products ratio remaining at 1 ). Moreover, both catalysts were much better than those of a reference nickel alumina catalyst prepared by conventional impregnation route. This work therefore demonstrates the possibility of using plastic wastes instead of commercial chemicals to prepare efficient porous nickel-alumina DRM catalysts from MOFs, fostering the concept of circular economy.
\end{abstract}

\section{Introduction}

Dry reforming of methane (DRM) is a promising approach for carbon dioxide valorization and syngas generation. This process uses $\mathrm{CH}_{4}$ and $\mathrm{CO}_{2}$ (greenhouse gases) originating from natural or renewable sources (biomass, municipal solid wastes) and converts them into the valuable carbon monoxide and hydrogen gases according to the equation:

\footnotetext{
${ }^{a}$ Department of Chemical Engineering, Faculty of Engineering, University of Balamand, P.O. Box 33 Amioun, El Koura, Lebanon

${ }^{b}$ Sorbonne Université, Campus UPMC, CNRS UMR-7197, Laboratoire de Réactivité de Surface, 4 Place Jussieu, 75005 Paris, France. E-mail: julien.reboul@sorbonneuniversite.fr

${ }^{c}$ Politecnico di Torino, Department of Applied Science and Technology, Corso Duca degli Abruzzi 24, 10129 Torino, Italy

$\dagger$ Electronic supplementary information (ESI) available. See DOI: 10.1039/ d0ma00984a

\# Present address: TWM - Technologies for Waste Management, Via Assietta 27, 10128 Torino, Italy.
}

$\mathrm{CH}_{4}(\mathrm{~g})+\mathrm{CO}_{2}(\mathrm{~g})=2 \mathrm{CO}(\mathrm{g})+2 \mathrm{H}_{2}(\mathrm{~g}) \cdot{ }^{1-3}$ The $\mathrm{H}_{2} / \mathrm{CO}$ ratio close to 1 makes DMR more interesting for the production of highadded products such as oxo-alcohols and light olefins via the Fischer-Tropsch synthesis, compared with methane steam reforming or partial oxidation. ${ }^{4-7}$ Despite its environmental and economic advantages, DRM is still not industrially applied. In the literature, there are only few cases of industrial demonstration, for example a plant able to transform up to 60 tons per day of $\mathrm{CO}_{2}$ via the autothermal dry reforming of $\mathrm{CO}_{2}$-rich natural gas for the production of linear $\mathrm{C}_{2}-\mathrm{C}_{15}$ olefins, with a selectivity higher than $90 \% .^{8}$ The main challenge that hinders the widespread applications of this virtuous process resides in the performances of the required catalyst. Catalysts with supported noble metals such as platinum, palladium, rhodium or ruthenium were found to be very active and stable $\mathrm{e}^{9-11}$ but they are expensive, and recent efforts are rather dedicated to the development of nickel-based catalysts due to the lower price and good activity of this transition metal. Although promising, the application of $\mathrm{Ni}^{0}$ as active phase for DRM is however hampered by 
stability issues related to the sensitivity of nickel towards sintering and to the frequent formation of carbonaceous deposits under the high reaction temperatures required for the DRM to proceed. Efforts have therefore been put to enhance the activity and stability of the catalyst by several ways like the formation of $\mathrm{Ni}^{\mathrm{O}}$ nanoparticles with reduced sizes, the addition of a second metal or promoter, ${ }^{12-14}$ altering the type of support used ${ }^{15-17}$ or enhancing the interaction between $\mathrm{Ni}$ and its carrier. ${ }^{18-21}$

In previous reports, our group described methods to obtain highly stable DRM catalysts based on Ni nanoparticles highly dispersed on silica and alumina supports..$^{20,22-25}$ In our latter contribution, the aluminum-based metal-organic framework (MOF) MIL-53(Al), a highly porous MOF composed of onedimensional infinite aluminum hydroxyl chains connected to one another by benzendicarboxylate (BDC) linkers (its chemical formula is $\left.[\mathrm{Al}(\mathrm{OH}) \mathrm{BDC}]_{x}\right)$, was employed as a hybrid alumina precursor. Its high porosity was exploited to disperse nickel cation precursors in close proximity to the inorganic cornerstones of the framework through an impregnation step. ${ }^{26}$ Calcination of the Ni-impregnated MIL-53(Al), carried out to remove the organic phase, resulted in a porous alumina phase within which Ni cations were homogeneously dispersed in the form of thermally stable nickel aluminate nanodomains. The formation of these nickel aluminate nano-crystallites is believed to be at the origin of the particularly high stability and small size of the nickel metal nanoparticles obtained after reduction. It may explain the remarkable performance of the prepared MOF-derived catalyst in DRM ( $\mathrm{CO}$ and $\mathrm{H}_{2}$ yield above $90 \%$ and $\mathrm{CO}: \mathrm{H}_{2}$ close to 1 for $100 \mathrm{~h}$ at $\left.650{ }^{\circ} \mathrm{C}\right) .{ }^{26,27}$

However, the benefit of this method, and more generally of any approach relying on the use of MOFs as sacrificial precursors for the production of porous carbons or metal oxides, is hampered by the irremediable loss of the organic part after the calcination step. De facto, although potentially promising in a range of applications and particularly in catalysis, ${ }^{28}$ sacrificial-MOFs-derived approaches thus suffer from the relatively high economic and environmental cost associated to the organic linkers production and to their degradation. Specifically, terephthalic acid $\left(\mathrm{C}_{8} \mathrm{H}_{4} \mathrm{O}_{4}\right.$, also termed benzene dicarboxylic acid, BDC), one of the most widely employed organic linkers in MOF synthesis, is industrially produced by the costly oxidation of petroleum-derived xylenes used as starting materials. This energy-intensive and multi-step process relies on several expensive metal catalysts and product purification operations. ${ }^{29}$ Strategies towards more sustainable synthesis of MOF-derived materials are still rare in the literature. One of them could be to use MOFs made from cheap linker sources derived from recycled organic feedstocks (such as domestic plastics), with the advantage of not only reducing the cost of MOF production but also to address issues related to waste remediation. ${ }^{30}$

Polyethylene terephthalate (PET) is a thermoplastics of the polyester family with chemical formula $\left(\mathrm{C}_{10} \mathrm{H}_{8} \mathrm{O}_{4}\right)_{n}$. It is synthesized from ethylene glycol $\left(\mathrm{C}_{2} \mathrm{H}_{6} \mathrm{O}_{2}\right)$ and terephthalic acid (named BDC, in the following). It is commonly used in the production of plastic bottles and containers as well as fibers for clothing and carpets. PET is one of the main plastics source in urban waste, with global production of $30.3 \times 10^{6}$ tons in $2017 .^{31}$
Because of its large production volume, its short useful life as a domestic package and its non-biodegradable property, recycling of PET becomes a growing environmental concern. ${ }^{32}$ Moreover, recycling plastic wastes is going in the direction of increasing the recycling rates, expected to reach $55 \%$ by 2030 for plastic packages, as imposed by the EU Commission, thus fostering the growing concept of circular economy. ${ }^{33,34}$ In this context, synthesizing MOFs from BDC issued from the depolymerization of PET was recently demonstrated to be a very attractive strategy to simultaneously lower the cost and the ecological footprint of MOF production and recycle the terephthalate component of PET. ${ }^{35}$ In this process, the depolymerization of PET occurs in the aqueous MOF synthesis medium by the hydrolysis of the ester bond that hold PET together, generating in turn the elementary BDC bricks. To our knowledge, this strategy was however not yet applied in the context of the preparation of carbonaceous or inorganic materials derived from the degradation of MOFs.

Herein, we demonstrate the feasibility of performing $\mathrm{Ni}^{0}$ $\mathrm{Al}_{2} \mathrm{O}_{3}$ DRM catalysts derived from an aluminum-terephthalate MIL-53(Al) synthesized by replacing commercial BDC with waste-sourced PET flakes within the hydrothermal synthesis mixture. The synthesis of MOF using PET is first validated by comparing the physicochemical characteristics of the MIL-53(Al) obtained from PET to those of a reference material prepared from the commercial BDC source. After Ni-impregnation, calcination and reduction, the catalytic performance in DRM of the thus produced $\mathrm{PET}$-derived $\mathrm{Ni}^{0}-\mathrm{Al}_{2} \mathrm{O}_{3}$ catalyst is monitored and compared to that of the BDC-derived $\mathrm{Ni}^{0}-\mathrm{Al}_{2} \mathrm{O}_{3}$ catalyst as well as to that of a particularly active ad stable MIL-53(Al)-derived $\mathrm{Ni}^{0}$ $\mathrm{Al}_{2} \mathrm{O}_{3}$ catalyst produced (from commercial BDC) by microwave from our previous work. ${ }^{26}$

\section{Experimental section}

\section{Materials preparation}

MIL-53(Al) syntheses from PET and commercial BDC. Clear colorless plastic PET bottles were collected from domestic wastes. The bottles were washed with water and soap, carefully rinsed with water and then dried. PET flakes were obtained by manually cutting the bottles into $5 \times 5 \mathrm{~mm}$ sized pieces with scissors. The flakes were then washed again with water, then with ethanol. MIL-53(Al) was synthesized by mixing $0.346 \mathrm{~g}$ of $\mathrm{AlCl}_{3} \cdot 6 \mathrm{H}_{2} \mathrm{O}, 0.5 \mathrm{~g}$ of PET flakes and $30 \mathrm{~mL}$ of deionized water in a $100 \mathrm{ml}$ Teflon-lined steel autoclave and heating it in an oven for $26 \mathrm{~h}$ at $200{ }^{\circ} \mathrm{C}$. At this point, it can be recalled that the number of BDC units in PET represents about $85 \mathrm{wt} \%$ of the polymer, as estimated from the molar weight of BDC $\left(\mathrm{C}_{8} \mathrm{H}_{4} \mathrm{O}_{4}\right.$, $164.11 \mathrm{~g} \mathrm{~mol}^{-1}$ ) compared to that of the full ethylene terephthalate repeating units $\left(\mathrm{C}_{10} \mathrm{H}_{8} \mathrm{O}_{4}, 192.17 \mathrm{~g} \mathrm{~mol}^{-1}\right)$. After the completion of the reaction, the autoclave was cooled down to room temperature naturally. The solid was recovered by vacuum filtration and washed with dimethylformamide (Sigma-Aldrich, 99.8\%), deionized water and finally with ethanol to ensure the full removal of aluminum and PET-derived residues. The solid was recovered by filtration, washed and dried at $80{ }^{\circ} \mathrm{C}$ (the washed 
sample is labelled MIL-53-PET ${ }_{\mathrm{w}}$ ). The same synthesis procedure was applied by replacing PET flakes by commercial (SigmaAldrich) BDC resulting in the reference sample MIL-53-BDC ${ }_{\mathrm{w}}$. In this synthesis, $0.425 \mathrm{~g}$ of commercial BDC was added to get an $\mathrm{Al} / \mathrm{BDC}$ molar ratio equal to that of the synthesis achieved from PET (Al/BDC molar ratio $=0.55$, assuming that the PET bottles are made of pure PET that fully depolymerizes under the condition of MIL-53(Al) synthesis). Pore evacuation was then achieved in both materials by a heat treatment at $330{ }^{\circ} \mathrm{C}$ for 3 days in static air (activated samples are labelled MIL-53-PET ${ }_{\mathrm{AC}}$ and $\mathrm{MIL}-53-\mathrm{BDC}_{\mathrm{AC}}$ ). Synthesis reaction yields were calculated with the following equation: (weight of MIL-53 obtained)/(weight of MIL-53(Al) expected) $\times 100$.

Catalysts preparation procedures. Nickel introduction was carried out by incipient wetness impregnation of both activated MIL-53-PET ${ }_{\mathrm{AC}}$ and MIL-53-BDC ${ }_{\mathrm{AC}}$ samples. These samples were dehydrated again at $80{ }^{\circ} \mathrm{C}$ in an oven overnight before impregnation to ensure their fully dehydrated state. The procedure consisted in adding dropwise a $\mathrm{Ni}\left(\mathrm{NO}_{3}\right)_{2} \cdot 6 \mathrm{H}_{2} \mathrm{O}$ aqueous solution with a volume equal to the pore volume of the activated MOF (as estimated from $\mathrm{N}_{2}$-sorption analysis) and a $\mathrm{Ni}$ concentration established as to correspond to a $\mathrm{Ni} / \mathrm{Al}$ atomic ratio in the sample of 0.07 (i.e., final Ni content in the dry catalyst of $5 \mathrm{wt} \%$ ). Each material was then dried at room temperature for $24 \mathrm{~h}$ and then at $200{ }^{\circ} \mathrm{C}$ for $15 \mathrm{~h}$ (impregnated samples Ni-MIL-53-PET Imp $_{\text {and Ni-MIL-53-BDC }}$ Imp). This was followed by calcination in static air at $500{ }^{\circ} \mathrm{C}$ for $5 \mathrm{~h}$ (heating rate $0.5{ }^{\circ} \mathrm{C} \mathrm{min}^{-1}$ ). Finally, these calcined materials (labeled $\mathrm{Ni}-$ $\mathrm{Al}_{2} \mathrm{O}_{3}-\mathrm{PET}$ and $\mathrm{Ni}-\mathrm{Al}_{2} \mathrm{O}_{3}-\mathrm{BDC}$ ) were thermally treated under hydrogen at $800{ }^{\circ} \mathrm{C}$ to form the reduced nickel nanoparticles that constitute the active phase for $\mathrm{DRM}\left(\mathrm{Ni}^{\mathrm{O}}-\mathrm{Al}_{2} \mathrm{O}_{3}-\mathrm{PET}\right.$ and $\mathrm{Ni}^{0}-\mathrm{Al}_{2} \mathrm{O}_{3}-\mathrm{BDC}$ catalysts).

Samples labelled as $\mathrm{Ni}^{0}-\mathrm{Al}_{2} \mathrm{O}_{3}-\mathrm{BDC}_{\mathrm{MW}}$ and $\mathrm{Ni}^{0}-\mathrm{Al}_{2} \mathrm{O}_{3}-\mathrm{COM}$ were synthesized for comparison purposes following a preparation procedure elaborated in details in our previous paper. ${ }^{26}$ Briefly, $\mathrm{Ni}^{0}-\mathrm{Al}_{2} \mathrm{O}_{3}-\mathrm{BDC}_{\mathrm{MW}}$ was synthesized following the same procedure as for $\mathrm{Ni}^{0}-\mathrm{Al}_{2} \mathrm{O}_{3}-\mathrm{PET}$ except that MIL-53 was synthesized under microwave irradiations. $\mathrm{Ni}^{0}-\mathrm{Al}_{2} \mathrm{O}_{3}-\mathrm{COM}$ was synthesized by incipient wetness impregnation of a commercial aluminum hydroxide $(\mathrm{AlOOH})$.

\section{Catalytic tests}

The catalytic performance of the prepared catalysts was studied in a fixed bed reactor (Hastelloy X, I.D. $=9 \mathrm{~mm}, L=30.5 \mathrm{~cm}$ ) situated inside a microactivity reference catalytic reactor unit (MAR, PID Eng and Tech, Spain). Typically, $50 \mathrm{mg}$ of catalyst was loaded into the reactor and reduced in situ under 5 vol\% $\mathrm{H}_{2} / \mathrm{Ar}\left(30 \mathrm{ml} \mathrm{min}{ }^{-1}\right)$ at $800{ }^{\circ} \mathrm{C}$ for $2 \mathrm{~h}$ (heating rate $\left.5{ }^{\circ} \mathrm{C} \mathrm{min}^{-1}\right)$. This protocol was chosen based on our previous study. ${ }^{26}$ The reactor was then cooled down to $200{ }^{\circ} \mathrm{C}$ and the reducing gas was replaced by a gas composed of an equimolar amount of $\mathrm{CH}_{4}$ and $\mathrm{CO}_{2}$ diluted in $\mathrm{Ar}$ (molar ratio 5/5/90) introduced at a gas hourly space velocity (GHSV) of $72 \mathrm{~L} \mathrm{~g}^{-1} \mathrm{~h}^{-1}$ and atmospheric pressure. The temperature was increased stepwise from $200{ }^{\circ} \mathrm{C}$ till $800{ }^{\circ} \mathrm{C}$ to investigate the activity profiles of the catalysts. Stability measurements were finally performed at $650{ }^{\circ} \mathrm{C}$ after cooling the reactor to this temperature. Chosen experiments were repeated to ensure reproducibility of catalytic results under the used conditions. The catalytic performance was established from the gas composition at the exit of the reactor monitored with an INFICON micro GC equipped with a TCD and two parallel channels (Molecular sieve and Plot $\mathrm{U}$ ). The data are reported from 0 to $13 \mathrm{~h}$ of reaction (stability test) in terms of:

- reactants conversions, estimated from the equation " $X$ conversion (\%) $=\left(C_{\text {in }}-C_{\text {out }}\right) / C_{\text {in }}$ ", where $C_{\text {in }}$ and $C_{\text {out }}$ represent the inlet and outlet concentrations of $\mathrm{CH}_{4}$ or $\mathrm{CO}_{2}$ gases, respectively,

- " $\mathrm{H}_{2}: \mathrm{CO}$ (mole ratio) $=M_{\mathrm{H}_{2}}: M_{\mathrm{CO}}$ ", where $M_{\mathrm{H} 2}$ and $M_{\mathrm{CO}}$ are the molar concentrations of the formed $\mathrm{H}_{2}$ and $\mathrm{CO}$ products.

Carbon balance was systematically verified during the tests and was always above $98 \%$.

\section{Physicochemical characterization techniques}

Powder X-ray diffraction patterns (PXRD) were recorded on a BRUKER type D8 diffractometer equipped with a $\mathrm{Cu} \mathrm{K} \alpha$ irradiation source $(\lambda=1.5405 \mathrm{~nm})$ and operating at $30 \mathrm{kV}$ and $10 \mathrm{~mA}$. The acquisitions were done in a $2 \theta$ range of 5 to $90^{\circ}$. Crystalline phase identification was based on comparison with standard PXRD files published by the international center for diffraction data (ICDD).

Thermogravimetric analysis was performed on a TA SDT Q600 instrument working in horizontal mode. One of the two alumina pan was filled with about $20 \mathrm{mg}$ of sample while the other (reference) pan was kept empty. The analysis was carried out in air flow (50 $\mathrm{ml} \mathrm{min}^{-1}$ ) from room temperature to $900{ }^{\circ} \mathrm{C}$ with a ramping rate of $5{ }^{\circ} \mathrm{C} \mathrm{min}^{-1}$.

Textural properties were evaluated from nitrogen adsorption-desorption isotherms recorded at $-198{ }^{\circ} \mathrm{C}$ with a BELSORP-max apparatus. The specific surface areas of the samples were determined with the standard BET procedure considering the relative equilibrium pressure interval of 0.05-0.3. The samples were degassed before measurements at $120{ }^{\circ} \mathrm{C}$ under vacuum for $6 \mathrm{~h}$.

Transmission electron microscopy (TEM) observations were done on ultrathin sections of solids to correctly visualize the dispersed nickel nanoparticles (and eventual carbon deposits) and their location inside or outside the porous alumina grains. The sections were prepared as follows: a few milligrams of powder were mixed with an EPON 812 embedding resin in a beam capsule. Polymerization of the mixture took place at $60{ }^{\circ} \mathrm{C}$ for $48 \mathrm{~h}$, then the polymerized blocks were cut with a diamond knife in slices (50-70 $\mathrm{nm}$ in thickness) that were deposited on copper grids covered with a carbon membrane layer. TEM images were taken on a JEOL-JEM 200 electron microscope operating at $200 \mathrm{keV}$ (LaB6gun). Average metallic $\mathrm{Ni}^{0}$ particle sizes were estimated considering at least 450 particles present in the grains imaged by TEM. Scanning Electron Microscopy (SEM) images were taken on a Hitachi SU-70 SEM-FEG microscope with an electron acceleration tension of $7 \mathrm{kV}$. After careful grinding, the samples were deposited on the analysis support and observed in mixed mode $(70 \%$ of secondary electrons and $30 \%$ of retro-diffused signals). 


\section{Results and discussion}

\section{Validation of the PET-derived MIL-53(Al) synthesis}

The quality of the MIL-53-PET synthesized by employing the depolymerization of PET flakes with a mean size of $5 \times 5 \mathrm{~mm}$ manually cut from domestic water bottles was attested by comparing its physicochemical characteristics with those of the reference MIL-53-BDC obtained from the commercial BDC powder conventionally used to synthesize MIL-53(Al). At the end of the hydrothermal synthesis, the as-synthesized MIL-53PET appears as a white precipitate dispersed in a brownish solution, whose color likely originates from the decomposition of the ethylene glycol formed during the PET hydrolysis. After thorough washing and recovery, no residual PET flakes were visually detected in the MIL-53-PET ${ }_{\mathrm{w}}$ powder. The X-ray diffractogram of MIL-53-PET $\mathrm{w}_{\mathrm{w}}$ after drying at $80{ }^{\circ} \mathrm{C}$ is similar to that of MIL-53- $\mathrm{BDC}_{\mathrm{w}}$ dried in the same conditions and corresponds to the pure as-synthesized form of MIL-53(Al) (Fig. 1A( $\left(\mathrm{a}^{\prime}\right.$ and $\left.\left.\mathrm{b}^{\prime}\right)\right){ }^{36}$ After activation at $330{ }^{\circ} \mathrm{C}$ for 3 days and partial rehydration (storage few days in room atmosphere), the diffractograms of the two materials (MIL-53-PET $\mathrm{AC}_{\mathrm{AC}}$ and MIL-53-BDC $\mathrm{AC}_{\mathrm{AC}}$ ) are again similar (Fig. $1 \mathrm{~A}(\mathrm{a}$ and $\mathrm{b})$ ). They both correspond mainly to the hydrated narrow-pore form of MIL-53(Al), characterized by the (200) and (110) reflections at $2 \theta=9.3^{\circ}$ and $12.5^{\circ}$, respectively, and they contain a small portion of still dehydrated large-pore phase, characterized by the (101) reflection at $2 \theta=8.7^{\circ} .{ }^{36}$ The $\mathrm{N}_{2}$ sorption isotherms of both activated MIL-53-PET $\mathrm{AC}_{\mathrm{AC}}$ and MIL-53$\mathrm{BDC}_{\mathrm{AC}}$ (dehydrated in situ before the measurement) are almost similar as well, corresponding to the Type I shape expected for highly microporous MOFs (Fig. 1B(a and b)). Their BET specific surfaces $\left(S=1412\right.$ and $1397 \mathrm{~m}^{2} \mathrm{~g}^{-1}$, respectively) as well as their pore volumes $\left(V=0.59\right.$ and $0.58 \mathrm{~cm}^{3} \mathrm{~g}^{-1}$, respectively) are almost the same and in good correspondence with those commonly determined for pure MIL-53. ${ }^{36}$ The thermograms of the two activated samples are also very close, showing a first small weight loss below $100{ }^{\circ} \mathrm{C}$ due to dehydration, then one main weight loss equal to $72 \%$ at $c a .600{ }^{\circ} \mathrm{C}$ that corresponds to the BDC degradation (Fig. 1C(a and b)). The plateau at $22 \%$ observed for $T>600{ }^{\circ} \mathrm{C}$ gives the estimation of the amount of $\mathrm{Al}_{2} \mathrm{O}_{3}$ formed at the end of the analysis. This profile is in good agreement with the $\mathrm{AlOH}(\mathrm{BDC})$ formula of MIL-53(Al). ${ }^{36}$ The fact that no additional weight loss corresponding to remaining PET is detected on the thermograms of MIL-53-PET confirms that the PET hydrolysis occurred until its total consumption during the PET-derived synthesis. Accordingly, the MIL-53(Al) synthesis reaction yields calculated for MIL-53-PET and MIL-53BDC were almost identical, and equal to $28 \%$ and $29 \%$ for the PET-derived and BDC-based syntheses, respectively. Therefore, using PET as a BDC source does not limit the extent of the MIL-53(Al) synthesis reaction. In addition, SEM analyses of the two MOFs were obtained as large micrometer scaled crystals (Fig. 2a and b). MIL-53-PET ${ }_{\mathrm{AC}}$ crystals display a rod-like morphology while MIL-53-BDC ${ }_{\mathrm{AC}}$ crystals are less elongated and exhibit an illdefined morphology. All these features attest the purity of the MIL-53(Al) obtained from recycled PET and therefore the possibility to use it as a promising alumina precursor for the synthesis of $\mathrm{Ni}^{0}-\mathrm{Al}_{2} \mathrm{O}_{3}$ catalysts.

Preparation and characteristics of the $\mathrm{Ni}^{\mathbf{0}}-\mathrm{Al}_{2} \mathrm{O}_{3}-\mathrm{PET}$ catalyst. Incipient wetness impregnation of activated MIL-53-PET ${ }_{\mathrm{AC}}$ with the nickel nitrate precursor followed by drying at $200{ }^{\circ} \mathrm{C}$ led to the Ni-MIL-53-PET Imp material, whose PXRD pattern (Fig. 1A(c)) shows peaks similar, although less intense, to those of the activated MOF before impregnation (MIL-53-PET ${ }_{\mathrm{AC}}$, Fig. $1 \mathrm{~A}(\mathrm{~b})$ ). The preservation of the crystal integrity is accompanied by a preservation of the crystal aspect, as shown on the SEM images presented in Fig. S1a and b (ESI $\dagger$ ). Noteworthy, no aggregated nickel species are detected on the crystal faces of the impregnated PET-derived MIL-53, suggesting the efficient penetration of the nickel precursor within its pores (Fig. 2b). The efficient nickel inclusion inside the porosity is further supported by the decrease
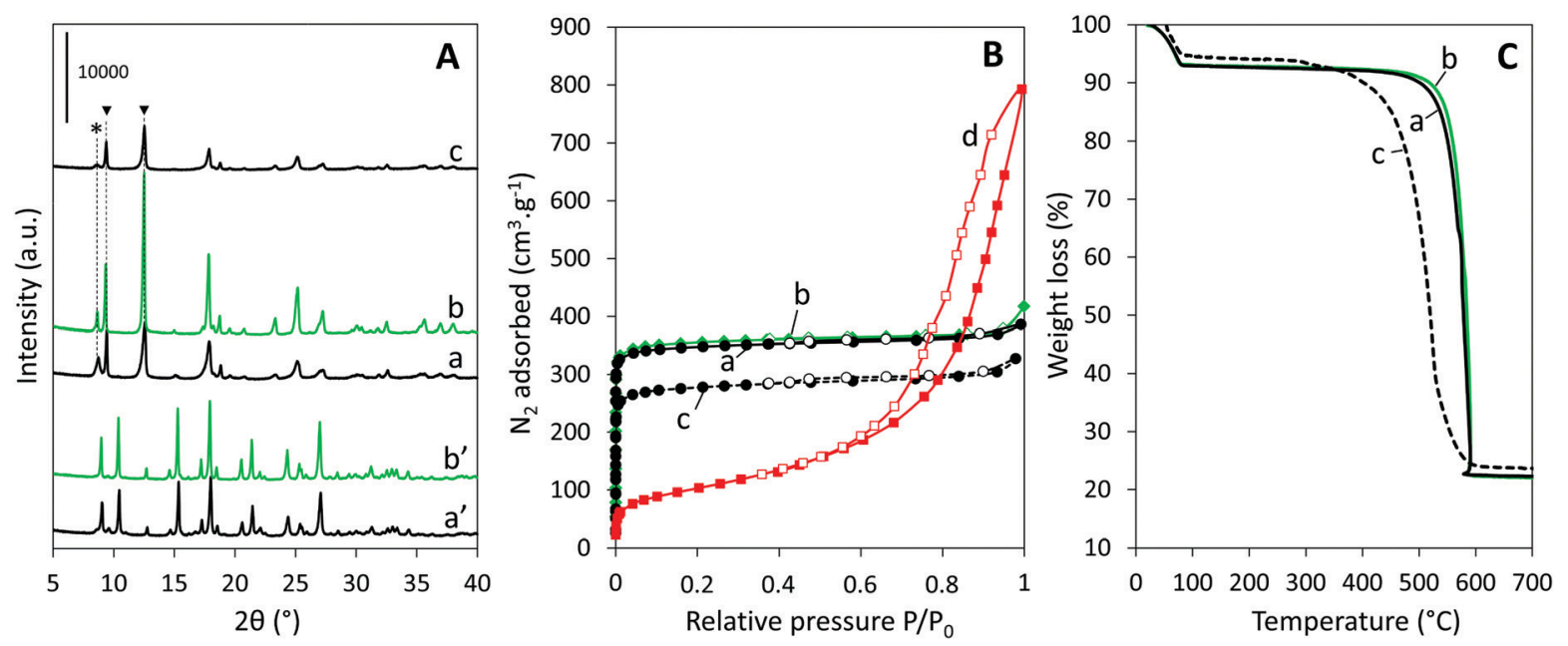

Fig. 1 (A) X-ray diffraction patterns, (B) $\mathrm{N}_{2}$ sorption isotherms, and (C) thermogravimetric profiles of ( $\left.a^{\prime}\right)$ washed as-synthesized MIL-53-PET ${ }_{w}$ and (b') MIL-53-BDC $w_{\text {, }}$ (a) activated MIL-53-PET AC and (b) MIL-53-BDC AC, $_{\text {, }}$ (c) impregnated Ni-MIL-53-PET Imp and (d) calcined Ni-Al $\mathrm{O}_{3}-\mathrm{PET}$. The star and the black triangles indicate the main peaks positions corresponding to the open and closed forms of the MIL-53(Al) structure, respectively (as reported in ref. 36). 

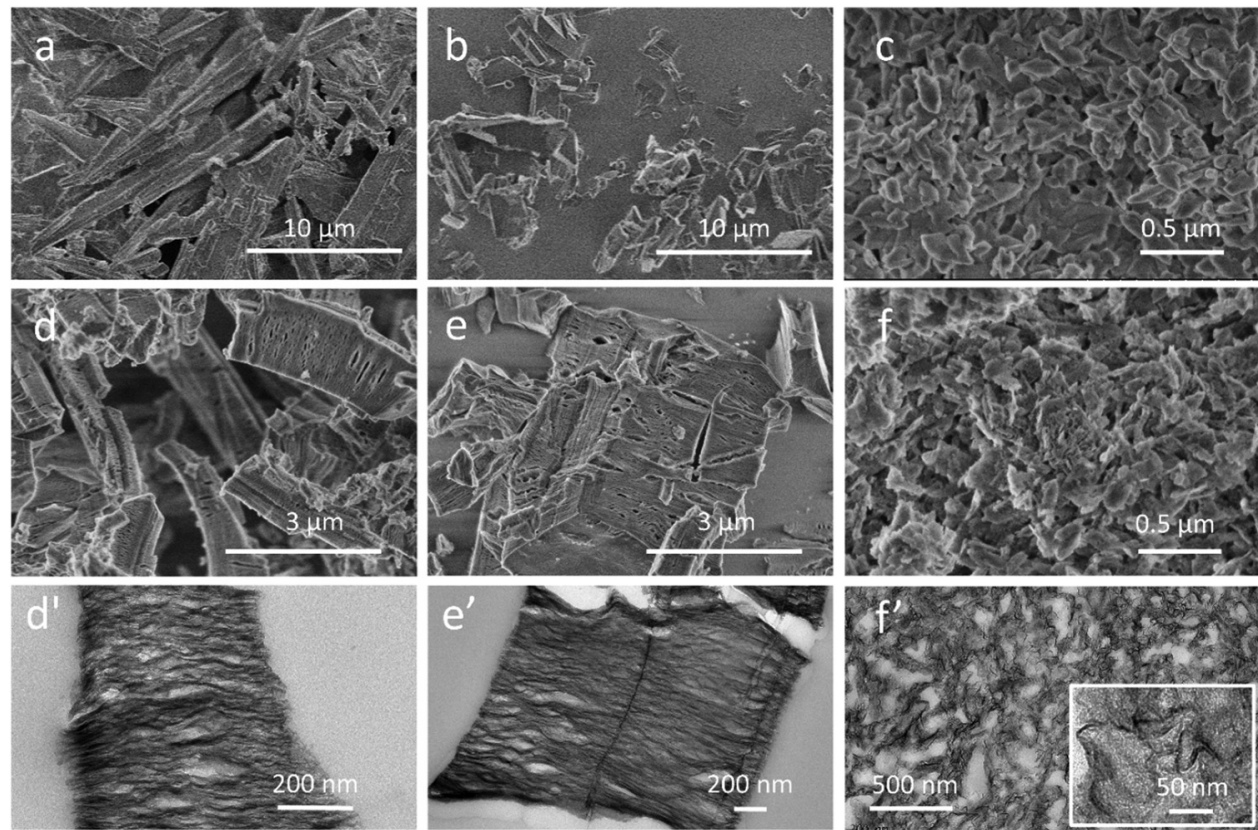

Fig. 2 (a-f) SEM and $\left(d^{\prime}-f^{\prime}\right)$ TEM images of activated (a) MIL-53-PET AC, $_{\text {, }}$ (b) MIL-53-BDC AC, $^{\text {, (c) MIL-53-BDC }}$ MWAC (from ref. 26) and of impregnated and calcined ( $d$ and $\left.d^{\prime}\right) \mathrm{Ni}-\mathrm{Al}_{2} \mathrm{O}_{3}-\mathrm{PET}$, (e and $e^{\prime}$ ) Ni-Al $\mathrm{O}_{3}-\mathrm{BDC}$ and ( $f$ and $f^{\prime}$ ) $\mathrm{Ni}-\mathrm{Al}_{2} \mathrm{O}_{3}-\mathrm{BDC}_{\mathrm{MW}}$ (from ref. 26). The TEM images were recorded on microtome cuts of the samples.

of the saturation volume of $\mathrm{N}_{2}$ adsorbed at low relative pressure $\left(P / P_{0}=0.02\right)$ in impregnated Ni-MIL-53-PET ${ }_{\text {Imp }}$ (Fig. $\left.1 \mathrm{~B}(\mathrm{c})\right)$ compared to activated MIL-53-PET ${ }_{\mathrm{AC}}$ (Fig. 1B(a)). This decrease indeed corroborates a pore hindrance linked to the presence of $\mathrm{Ni}^{2+}$. Accordingly, the microporous volume drops from $0.60 \mathrm{~cm}^{3} \mathrm{~g}^{-1}$ to $0.50 \mathrm{~cm}^{3} \mathrm{~g}^{-1}$ upon nickel impregnation and the BET specific surface area also diminishes from $1412 \mathrm{~m}^{2} \mathrm{~g}^{-1}$ to $1106 \mathrm{~m}^{2} \mathrm{~g}^{-1}$. The intimate mixing between the nickel precursor species and MIL-53PET framework is furthermore attested by the results of thermogravimetric analysis that still show a sudden main weight loss of about $66 \%$ at rather high temperature (between 400 and $590{ }^{\circ} \mathrm{C}$ ) but also an additional slow one of about $10 \%$ between 300 and $400{ }^{\circ} \mathrm{C}$ (Fig. 1C(c)). The latter is assignable to the thermal decomposition of nitrates introduced together with nickel during the impregnation step, as demonstrated by mass spectroscopy analysis of TGA exhaust gases in our previous study on BCD-derived Ni-MIL-53. ${ }^{26}$ In this previous study, we proposed that the oxidizing nitrogen oxide species (NOx gases) produced within the pores during nitrates decomposition promoted the degradation of the organic linkers in their vicinity, which explains the lowering by almost $100{ }^{\circ} \mathrm{C}$ of the temperature at which the framework degrades (significant weight loss centered around $450{ }^{\circ} \mathrm{C}$ for Ni-MIL-53-PET ${ }_{\text {Imp }}$ instead of around $550{ }^{\circ} \mathrm{C}$ for MIL-53-PET ${ }_{\mathrm{AC}}$ ).

The TG profiles prompted us to set the calcination temperature of impregnated Ni-MIL-53-PET Imp $_{\text {(and of reference Ni-MIL- }}$ $53-\mathrm{BDC}_{\text {Imp }}$ ) at $500{ }^{\circ} \mathrm{C}$ in order to form subsequently the porous $\mathrm{Ni}-\mathrm{Al}$ mixed oxide intermediate phases (labeled $\mathrm{Ni}-\mathrm{Al}_{2} \mathrm{O}_{3}-\mathrm{PET}$ and $\mathrm{Ni}-\mathrm{Al}_{2} \mathrm{O}_{3}-\mathrm{BDC}$, respectively). This temperature is indeed appropriate to guarantee the total degradation of the linkers while preserving a significant porosity and a large surface area in the calcined material. ${ }^{26}$ A first effect of the calcination at $500{ }^{\circ} \mathrm{C}$ is the transformation of MOF crystals into materials with a rod-like shape clearly deriving from the original MOF shapes (Fig. 2d). Independently of the PET-derived or BDC-derived synthesis route, the sudden departure of the organics from MOF crystals during calcination induces a drastic volume contraction of the whole material on which cracks and cavities are already clearly seen by SEM (Fig. 2d and e). They are better visualized on the TEM images of microtomic cuts of the samples made perpendicularly to the lamellae (Fig. $2 \mathrm{~d}^{\prime}$ and $\mathrm{e}^{\prime}$ ), where both impregnated and then calcined MOFs look like each other. Micrographs taken at higher magnification of $\mathrm{Ni}-\mathrm{Al}_{2} \mathrm{O}_{3}-\mathrm{PET}$ (Fig. 3a) and $\mathrm{Ni}-\mathrm{Al}_{2} \mathrm{O}_{3}-\mathrm{BDC}$ (Fig. S2A, ESI $\dagger$ ) show that the crystals are actually formed of corrugated lamellae packed along a main axis. The formation of interlamellar pores is also confirmed by $\mathrm{N}_{2}$ sorption analysis that displays a gradual increase of adsorbed $\mathrm{N}_{2}$ on the $P / P_{0}$ range from 0.6 to 1 and a slit-like hysteresis characteristic of interlamellar spaces (Fig. $1 \mathrm{~B}(\mathrm{~d})$ for $\mathrm{Ni}-\mathrm{Al}_{2} \mathrm{O}_{3}-\mathrm{PET}$ and Fig. $\mathrm{S} 3 \mathrm{~A}(\mathrm{~b})$ (ESI $\dagger$ ) for $\left.\mathrm{Ni}-\mathrm{Al}_{2} \mathrm{O}_{3}-\mathrm{BDC}\right)$. Pore size distributions of all samples are shown in Fig. S4 (ESI $\dagger$ ). The related specific surface area and pore volume are equal to 356 (resp. 352) $\mathrm{m}^{2} \mathrm{~g}^{-1}$ and 1.12 (resp. 0.99) $\mathrm{cm}^{3} \mathrm{~g}^{-1}$ for the PET-derived (resp. BDC-derived) Ni-alumina material.

The PXRD pattern of the lamellar $\mathrm{Ni}-\mathrm{Al}_{2} \mathrm{O}_{3}-\mathrm{PET}$ (Fig. $3 \mathrm{~b}$, bottom curve, see Fig. S3B (ESI $\dagger$ ) for the PXRD pattern of $\mathrm{Ni}-$ $\left.\mathrm{Al}_{2} \mathrm{O}_{3}-\mathrm{BDC}\right)$ exhibits three main very broad peaks corresponding to a cubic spinel $\mathrm{NiAl}_{2} \mathrm{O}_{4}$ phase with (311), (400) and (440) planes giving main peaks at $2 \theta=37.0^{\circ}, 45.0^{\circ}$ and $65.0^{\circ} .^{26}$ The broad peaks at $37^{\circ}$ and $45^{\circ}$ are asymmetric and may also contain overlaid peaks of $\gamma-\mathrm{Al}_{2} \mathrm{O}_{3}$, which suggests that the lamellae are made of $\mathrm{NiAl}_{2} \mathrm{O}_{4}$ nano-crystallites dispersed within poorly crystalline alumina. The very high nickel dispersion is also illustrated by the absence of any detectable nickel oxide 

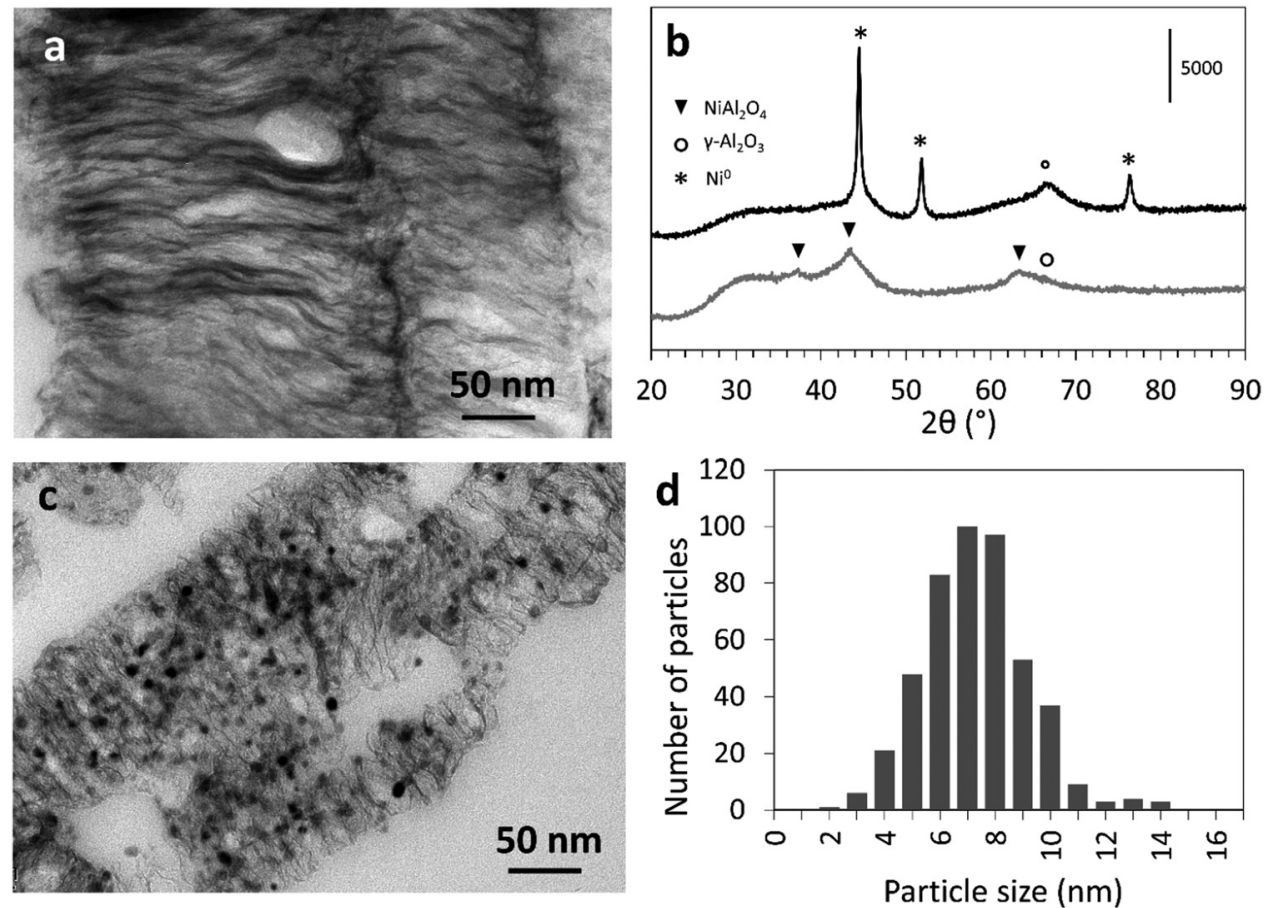

Fig. 3 (a) TEM image of a microtome cut of $\mathrm{Ni}-\mathrm{Al}_{2} \mathrm{O}_{3}-\mathrm{PET}$, (b) PXRD patterns of $\mathrm{Ni}-\mathrm{Al}_{2} \mathrm{O}_{3}-\mathrm{PET}$ (grey line, bottom) and of $\mathrm{Ni}^{\mathrm{O}}-\mathrm{Al}_{2} \mathrm{O}_{3}-\mathrm{PET}$ (black line top), (c) TEM image of a microtome cut of $\mathrm{Ni}^{0}-\mathrm{Al}_{2} \mathrm{O}_{3}-\mathrm{PET}$ and (d) histogram established from at least $450 \mathrm{Ni}^{\circ}$ nanoparti cles in typical TEM images of $\mathrm{Ni}^{\circ}-\mathrm{Al}_{2} \mathrm{O}_{3}-$ PET.

nanoparticles in the TEM images. In addition, the strong interaction of the nickel cations with the aluminum oxide phase is supported by the high reduction temperature $\left(T>700{ }^{\circ} \mathrm{C}\right)$ determined by TPR analysis (Fig. S5, ESI $\dagger$ ).

Reduction of the $\mathrm{Ni}-\mathrm{Al}_{2} \mathrm{O}_{3}-\mathrm{PET}$ at $\mathrm{T}=800{ }^{\circ} \mathrm{C}$ under $\mathrm{H}_{2}$, leading to the $\mathrm{Ni}^{0}-\mathrm{Al}_{2} \mathrm{O}_{3}$-PET catalyst, induced the formation of $\mathrm{Ni}^{0}$ nanoparticles occluded within the interlamellar spaces (Fig. 3c) and characterized by a narrow size distribution centered on $7.5 \mathrm{~nm}$ ((Fig. 3d), top curve). The simultaneous appearance of new PXRD peaks assignable to the (111), (200) and (220) planes of crystalline $\mathrm{Ni}^{\circ}$ (at $2 \theta=44.5^{\circ}, 51.9^{\circ}$ and $76^{\circ}$, respectively) and the shift of the peak at $2 \theta=65.0^{\circ}$ (compared to that before reduction) towards a position characteristic of pure $\gamma-\mathrm{Al}_{2} \mathrm{O}_{3}$ attest the $\mathrm{Ni}$ extraction from the oxide matrix towards the lamellae surface (Fig. 3b, top curve). Application of the Scherrer's equation to the $\mathrm{Ni}^{0}$ reflection at $2 \theta=51.9^{\circ}$ leads to a mean $\mathrm{Ni}^{0}$ nanoparticle size of $5 \mathrm{~nm}$, in the same range even if slightly smaller than the value estimated by TEM. The sizes of the $\mathrm{Ni}^{0}$ nanoparticles are slightly less homogeneous in the BDC-derived $\mathrm{Ni}^{0}-\mathrm{Al}_{2} \mathrm{O}_{3}-\mathrm{BDC}$ catalyst (Fig. S2B and C, ESI $\dagger$ ). This may be due to a lower control (e.g., imperfect stirring) during preparation of this sample that was one of the first to be prepared using this new MOF-based strategy.
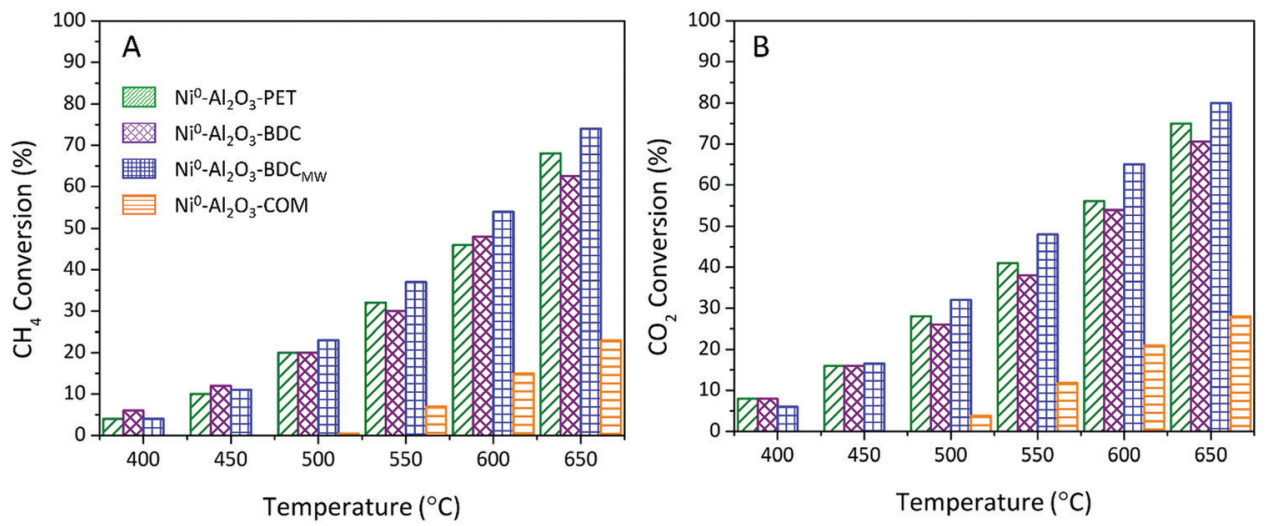

Fig. 4 (A) $\mathrm{CH}_{4}$ and (B) $\mathrm{CO}_{2}$ conversions during DRM upon continuous increase of temperature from $400{ }^{\circ} \mathrm{C}$ till $650{ }^{\circ} \mathrm{C}$ over in situ reduced $\left(800{ }^{\circ} \mathrm{C} / 2 \mathrm{~h}\right.$ ) catalysts: $\mathrm{Ni}^{\mathrm{O}}-\mathrm{Al}_{2} \mathrm{O}_{3}-\mathrm{PET}$ (green tilted stripes), $\mathrm{Ni}^{\mathrm{O}}-\mathrm{Al}_{2} \mathrm{O}_{3}-\mathrm{BDC}$ (purple diamond grid), $\mathrm{Ni}^{\circ}-\mathrm{Al}_{2} \mathrm{O}_{3}-\mathrm{BDC}_{\mathrm{MW}}{ }^{26}$ (blue square grid), and $\mathrm{Ni}^{\mathrm{O}}-\mathrm{Al}_{2} \mathrm{O}_{3}-\mathrm{COM}^{26}$ (orange horizontal stripes). 
Catalytic performance. Fig. 4 shows the results of the activity tests performed at increasing temperatures on $\mathrm{Ni}^{0}-\mathrm{Al}_{2} \mathrm{O}_{3}-\mathrm{PET}$ and $\mathrm{Ni}^{0}-\mathrm{Al}_{2} \mathrm{O}_{3}-\mathrm{BDC}$. They are expressed as $\mathrm{CH}_{4}$ and $\mathrm{CO}_{2}$ conversions and are compared to those obtained on two additional reference catalysts studied in our previous work dealing with the MOF-based synthesis of $\mathrm{Ni}^{0}-\mathrm{Al}_{2} \mathrm{O}_{3}$ materials. ${ }^{26}$ On the one hand, $\mathrm{Ni}^{0}-\mathrm{Al}_{2} \mathrm{O}_{3}-\mathrm{BDC}_{\mathrm{MW}}$, was synthesized following the same procedure as for $\mathrm{Ni}^{0}-\mathrm{Al}_{2} \mathrm{O}_{3}-\mathrm{BDC}$ except that microwave irradiation was used to perform the MOF synthesis, instead of the conventional oven used here, and this resulted in the formation of nanoscopic MIL-53(Al) crystals (with size below $50 \mathrm{~nm}$, Fig. 2c, $\mathrm{f}$ and $\left.\mathrm{f}^{\prime}\right) \cdot \mathrm{Ni}^{0}-\mathrm{Al}_{2} \mathrm{O}_{3}-\mathrm{COM}$, on the other hand, was prepared by standard wetness Ni-impregnation of a commercial $\gamma-\mathrm{Al}_{2} \mathrm{O}_{3}$ support. ${ }^{26}$ For all catalysts, an increase of both $\mathrm{CH}_{4}$ and $\mathrm{CO}_{2}$ conversions with temperature is observed, in accordance with the endothermic behavior of the DRM reaction. A slightly higher $\mathrm{CO}_{2}$ than $\mathrm{CH}_{4}$ conversion is also depicted over the entire temperature range accounting for some but limited occurrence of RWGS (Reverse Water Gas Shift) that consumes $\mathrm{CO}_{2}$ and increases its conversion level. ${ }^{37,38}$

Remarkably, the conversion of both reactants starts to be observed on $\mathrm{Ni}^{0}-\mathrm{Al}_{2} \mathrm{O}_{3}-\mathrm{PET}, \mathrm{Ni}^{0}-\mathrm{Al}_{2} \mathrm{O}_{3}-\mathrm{BDC}$ and $\mathrm{Ni}^{0}-\mathrm{Al}_{2} \mathrm{O}_{3}$ $\mathrm{BDC}_{\mathrm{MW}}$ from $400{ }^{\circ} \mathrm{C}$, while it appears only at $500{ }^{\circ} \mathrm{C}$ on commercial $\mathrm{Ni}^{0}-\mathrm{Al}_{2} \mathrm{O}_{3}$-COM. This starting of conversion at lower temperature reveals a higher activity, also attested by the systematically much higher $\mathrm{CH}_{4}$ and $\mathrm{CO}_{2}$ conversions on MOF-derived catalysts, compared to $\mathrm{Ni}^{0}-\mathrm{Al}_{2} \mathrm{O}_{3}$-COM, whatever the reaction temperature. More importantly, the conversion on $\mathrm{Ni}^{0}-\mathrm{Al}_{2} \mathrm{O}_{3}$-PET is as good - or even better - as that on $\mathrm{Ni}^{0}$ $\mathrm{Al}_{2} \mathrm{O}_{3}-\mathrm{BDC}$ prepared by following the exact same route, except for the BDC origin (either waste- or chemical-derived). It is however slightly lower than that on $\mathrm{Ni}^{0}-\mathrm{Al}_{2} \mathrm{O}_{3}-\mathrm{BDC}_{\mathrm{MW}}$, especially at $T>450{ }^{\circ} \mathrm{C}$, due to its distinct morphology as will be further discussed below. In addition, $\mathrm{Ni}^{0}-\mathrm{Al}_{2} \mathrm{O}_{3}-\mathrm{PET}$ displays a very high stability, with no change in conversions for $13 \mathrm{~h}$ at $650{ }^{\circ} \mathrm{C}$ under reactant stream, as for the other MOF-derived catalyst and much better than on $\mathrm{Ni}^{0}-\mathrm{Al}_{2} \mathrm{O}_{3}$-COM (Fig. $5 \mathrm{~A}$ and $\mathrm{B}$ ). $\mathrm{Ni}^{0}-\mathrm{Al}_{2} \mathrm{O}_{3}$-PET selectivity towards DRM reaction is excellent as well as indicated by the obtained $\mathrm{H}_{2}$ : $\mathrm{CO}$ molar ratio that keeps always very close to 1 (0.99), as for $\mathrm{Ni}^{0}-\mathrm{Al}_{2} \mathrm{O}_{3}-\mathrm{BDC}$ (Fig. $5 \mathrm{C}$ ).
In view of the structural purity of the MIL-53(Al) sacrificial phase obtained above from the PET wastes source (sample MIL$53-\mathrm{PET}_{\mathrm{AC}}$ ), the remarkable performance of the $\mathrm{Ni}^{0}-\mathrm{Al}_{2} \mathrm{O}_{3}-\mathrm{PET}$ catalyst, higher than that of the standard catalyst $\left(\mathrm{Ni}^{\mathrm{O}}-\mathrm{Al}_{2} \mathrm{O}_{3}\right.$ $\mathrm{COM}$ ) and similar to those of the catalysts made from commercial BDC $\left(\mathrm{Ni}^{0}-\mathrm{Al}_{2} \mathrm{O}_{3}-\mathrm{BDC}\right.$ and $\left.\mathrm{Ni}^{\mathrm{O}}-\mathrm{Al}_{2} \mathrm{O}_{3}-\mathrm{BDC}_{\mathrm{MW}}\right)$, were expected. Notably, the production of $\mathrm{Ni}^{0}-\mathrm{Al}_{2} \mathrm{O}_{3}$ from PET-derived MIL-53 occurs via the generation of the same nickel aluminate intermediate species than in the synthesis of $\mathrm{Ni}^{0}-\mathrm{Al}_{2} \mathrm{O}_{3}-\mathrm{BDC}_{\mathrm{MW}}$ (or $\mathrm{Ni}^{0}-\mathrm{Al}_{2} \mathrm{O}_{3}-\mathrm{BDC}$ ), which we previously identified as key intermediates for the production of a highly active and stable $\mathrm{Ni}^{0}-\mathrm{Al}_{2} \mathrm{O}_{3}$ catalyst. $^{27}$ Indeed, we recently proposed that the improved stability of the $\mathrm{Ni}^{2+}$ ions isolated within nickel aluminate nanodomains in the calcined materials slows down their extraction from the support during the reducing step, thus contributing to the formation of highly stable small nanoparticles. The strong interaction between $\mathrm{Ni}^{0}$ nanoparticles and the $\mathrm{Al}_{2} \mathrm{O}_{3}$ support, and thereby the improved stability of the catalyst, is assumed to be due to remaining $\mathrm{NiAl}_{2} \mathrm{O}_{4}$ phases acting as a "glue" at the nanoparticle $/ \mathrm{Al}_{2} \mathrm{O}_{3}$ interface. This strong interaction is believed to inhibit not only nickel sintering but also the potential formation of carbon nanotubes, ${ }^{26,39}$ which growth is caused by the presence of weakly attached nickel particles able to move far away from the support itself by being embedded at the tip of the nanotubes while these nanotubes form.

The better performance observed with $\mathrm{Ni}^{0}-\mathrm{Al}_{2} \mathrm{O}_{3}-\mathrm{BDC}_{\mathrm{MW}}$ compared to those obtained with MIL-53-PET and MIL-53BDC can be likely related to the nanoscopic size of the MIL-53(Al) crystals from which this catalyst derives. In fact, there is an inversely proportional relationship between the size of nanoparticles and the $\mathrm{CH}_{4}$ conversion. MIL-53-BDC ${ }_{\mathrm{MW}}$ crystal size ranges from 50 to $100 \mathrm{~nm}$ while the sizes of crystals of MIL53-PET and MIL-53-BDC are both in the macroscopic regime, being comprised between $1 \mu \mathrm{m}$ and more than $10 \mu \mathrm{m}$ (Fig. 2a-c). Two hypotheses may explain why the nanosize of MIL-53-BDC $\mathrm{MW}_{\mathrm{MW}}$ crystals favors the catalytic performances of $\mathrm{Ni}^{0}-\mathrm{Al}_{2} \mathrm{O}_{3}-\mathrm{BDC}_{\mathrm{MW}}$. First, downsizing MIL-53(Al) crystals may enhance the dispersion of the Ni precursor during the impregnation step, resulting after calcination, in a better dispersion of $\mathrm{Ni}^{2+}$ within the $\mathrm{Al}_{2} \mathrm{O}_{3}$ matrix and, in turn, in slightly smaller $\mathrm{Ni}^{0}$ nanoparticles after reduction.
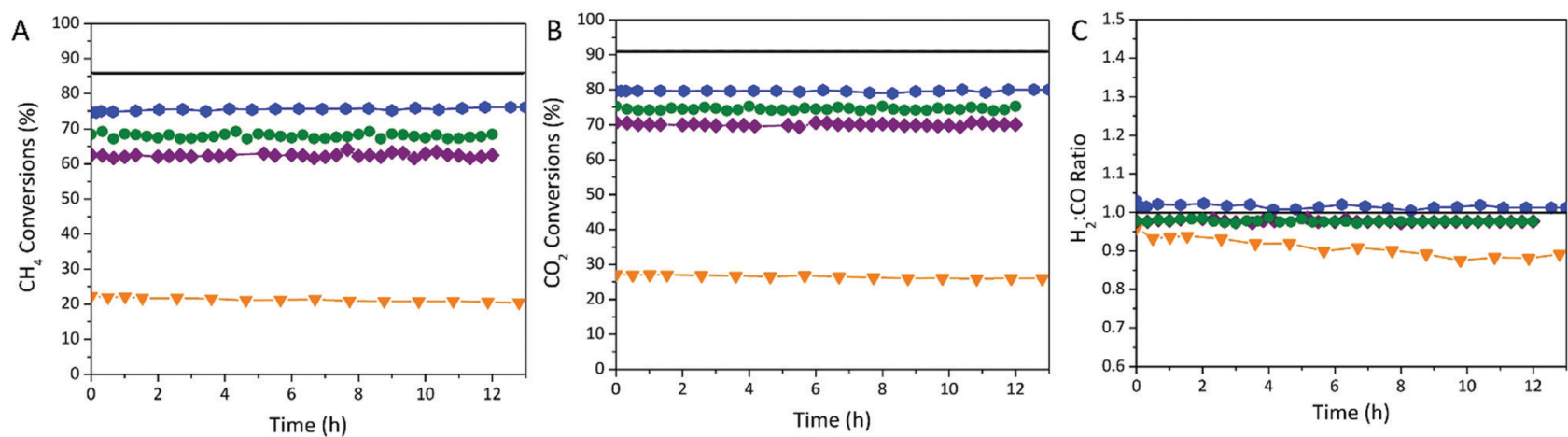

Fig. 5 Catalytic performance and stability of the catalysts during $13 \mathrm{~h}$ of $\mathrm{DRM}$ reaction: $\mathrm{Ni}^{\mathrm{O}}-\mathrm{Al}_{2} \mathrm{O}_{3}-\mathrm{PET}$ (green spheres), $\mathrm{Ni}^{\mathrm{O}}-\mathrm{Al} \mathrm{O}_{3}-\mathrm{BDC}$ (purple diamonds), $\mathrm{Ni}^{\mathrm{O}}-\mathrm{Al}_{2} \mathrm{O}_{3}-\mathrm{BDC}_{\mathrm{MW}}$ (blue spheres) and $\mathrm{Ni}^{\mathrm{O}}-\mathrm{Al}_{2} \mathrm{O}_{3}-\mathrm{COM}$ (orange triangles): (A) $\mathrm{CH}_{4}$ conversion, (B) $\mathrm{CO}_{2}$ conversion and (C) $\mathrm{H}_{2}$ : $\mathrm{CO}$ ratios. Black continued lines are the calculated values at the thermodynamic equilibrium for $\mathrm{CH}_{4}$ and $\mathrm{CO}_{2}$ conversions. 
A slightly lower size of $\mathrm{Ni}^{0}$ nanoparticles were indeed detected in $\mathrm{Ni}^{0}-\mathrm{Al}_{2} \mathrm{O}_{3}-\mathrm{BDC}_{\mathrm{MW}}$ compared to $\mathrm{Ni}^{0}-\mathrm{Al}_{2} \mathrm{O}_{3}-\mathrm{PET}$ and $\mathrm{Ni}^{0}-\mathrm{Al}_{2} \mathrm{O}_{3}-$ BDC (size $=6.8 \mathrm{~nm}^{26}$ against $7.5 \mathrm{~nm}$ in $\mathrm{Ni}^{0}-\mathrm{Al}_{2} \mathrm{O}_{3}-\mathrm{PET}$, Fig. 3). A decrease of the size of metal $\mathrm{Ni}$ nanoparticles is expected to increase the number of working active $\mathrm{Ni}^{0}$ sites and hence to enhance the catalytic activity in DRM reaction with higher turnover frequency values. ${ }^{40}$ Moreover, the presence of $\mathrm{Ni}^{0}$ nanoparticles can favor also the stability of the catalyst, since it is well-know that large $\mathrm{Ni}$ particle cause severe coke deposition. ${ }^{41,42}$ In this regard, it is noted that carbon deposits (graphitic and disordered carbon deposits) were detected by RAMAN spectroscopy on the spent $\mathrm{Ni}^{0}-\mathrm{Al}_{2} \mathrm{O}_{3}-$ PET catalyst (Fig. S6, ESI $\dagger$ ), which was not the case for the spent $\mathrm{Ni}^{0}-\mathrm{Al}_{2} \mathrm{O}_{3}-\mathrm{BDC}_{\mathrm{MW}}{ }^{21}$ Second, combustion of the nanosized Ni-impregnated MIL-53-BDC ${ }_{\mathrm{MW}}$ crystals results after combustion in Ni-containing alumina nanosheets with size of few tenths of nanometers (Fig. $2 \mathrm{f}^{\prime}$ and ref. 26) that are much smaller as well as more curved and interwoven than in $\mathrm{Ni}^{0}-\mathrm{Al}_{2} \mathrm{O}_{3}-\mathrm{PET}$ and $\mathrm{Ni}^{0}-\mathrm{Al}_{2} \mathrm{O}_{3}-\mathrm{BDC}$ (Fig. $2 \mathrm{~d}^{\prime}$ and $\left.\mathrm{e}^{\prime}\right)$. These mesostructure differences most likely imply differences in the surface chemistry properties (regarding the coordinated environment of $\mathrm{Al}^{3+}$ and the quantity of surface hydroxyl groups) of the $\gamma-\mathrm{Al}_{2} \mathrm{O}_{3}$ supports obtained after the $\mathrm{Ni}^{2+}$ reduction step. The effect of the alumina support properties were recently shown to drastically alter the catalytic activity of alumina supported catalysts, including $\mathrm{Ni}^{0}-\mathrm{Al}_{2} \mathrm{O}_{3} \cdot{ }^{43,44}$ One can for instance assume that the nanosheets of $\mathrm{Ni}^{0}-\mathrm{Al}_{2} \mathrm{O}_{3}-\mathrm{BDC}_{\mathrm{MW}}$ possess more basic sites, which readily and stably adsorb $\mathrm{CO}_{2}$ to form bicarbonate and thereby facilitate the DRM reaction. In view of its interest, work is going on this aspect that was however not the central scope of the present work.

\section{Conclusion}

In this work we demonstrated the possibility of lowering the economic and environmental impact of the synthesis of $\mathrm{Ni}^{0}$ $\mathrm{Al}_{2} \mathrm{O}_{3}$ catalysts made from MOFs by employing recycled PET, originating from plastic wastes, as organic linker source. The recycling of PET can be envisaged in the growing interest towards the circular economy. Physico-chemical properties as well as the synthesis yield of the MIL-53(Al) made from PET were first shown to be identical to those of the same MOF made from commercial benzene dicarboxylic acid, confirming that the depolymerization process providing BDC during the course of MOF synthesis does not affect the crystallization of MIL-53(Al). Calcination followed by reduction of the nickelimpregnated MIL-53(Al) derived from PET led to the formation of a mesostructured $\mathrm{Ni}^{0}-\mathrm{Al}_{2} \mathrm{O}_{3}$ catalyst composed of uniform $\mathrm{Ni}^{0}$ nanoparticles homogeneously dispersed on interwoven alumina lamellae. The performance of this catalyst in DRM reaction, both in terms of $\mathrm{CH}_{4}$ and $\mathrm{CO}_{2}$ conversions, selectivity and stability, was as good as those of $\mathrm{Ni}^{0}-\mathrm{Al}_{2} \mathrm{O}_{3}$ catalysts obtained from commercial BDC, and much better than a conventionally prepared equivalent catalyst. This study therefore shows that MOFs synthesized from cheap recycled organic precursors can be transformed into materials with properties as good as those of materials obtained from commercial sources. The environmental and economic cost related to the loss of BDC during the transformation of MIL-53(Al) into the catalyst is compensated by the benefits provided by the recycling of PET waste, namely the remediation of plastic wastes accumulation in the environment and the avoidance of industrially produced organic linkers from petroleum-derived molecules. Furthermore, also replacing the metal salts commonly used for MOF synthesis (chloride or nitrate metal salts) by more sustainable metal sources, such as natural or recycled metal oxides or metal sources derived from domestic wastes, would enable the implementation of even more sustainable routes for the synthesis of MOF-derived catalysts, enhancing the circular economy. This aspect is currently under study in our lab.

\section{Conflicts of interest}

The authors declare no conflict of interest.

\section{Acknowledgements}

The authors sincerely acknowledge the ERANET EU-FP7 initiative, the national ANR (France), CNRS-L (Lebanon) and MIUR (Italy) agencies for their support and funding through the SOLCARE (Energy-065) project (JC-ENERGY-2014 first call). The University of Balamand Research Council is also thanked for the BIRG 02/2016 contribution. Sandra Casale is warmly thanked for her invaluable contribution to the electron microscopy observations. Jean-Marc Krafft is warmly thanked for his contribution to the RAMAN spectroscopy analyses of the spent catalysts. AM gratefully acknowledges the Erasmus + Programme Countries scholarship for her stay at the Sorbonne University.

\section{References}

1 W. L. Luyben, J. Process Control, 2016, 39, 77-87.

2 Z. Navas-Anguita, P. L. Cruz, M. Martín-Gamboa, D. Iribarren and J. Dufour, Fuel, 2019, 235, 1492-1500.

3 Y. Gao, J. Jiang, Y. Meng, F. Yan and A. Aihemaiti, Energy Convers. Manage., 2018, 171, 133-155.

4 J. E. A. Graciano, A. D. Carreira, R. Giudici and R. M. B. Alves, Production of Fuels from $\mathrm{CO}_{2}$-rich Natural Gas using FischerTropsch Synthesis Coupled to Trireforming Process, Elsevier Masson SAS, 2017, vol. 40.

5 E. Akiki, D. Akiki, C. Italiano, A. Vita, R. Abbas-Ghaleb, D. Chlala, G. Drago Ferrante, M. Laganà, L. Pino and S. Specchia, Int. J. Hydrogen Energy, 2020, 45, 21392-21408. 6 T. V. Choudhary and V. R. Choudhary, Angew. Chem., Int. Ed., 2008, 47, 1828-1847.

7 L. Pino, C. Italiano, A. Vita, M. Laganà and V. Recupero, Appl. Catal., B, 2017, 218, 779-792.

8 Q. Chen, D. Wang, Y. Gu, S. Yang, Z. Tang, Y. Sun and Q. Wu, Energy Convers. Manage., 2020, 205, 112348.

9 Z. Hou, P. Chen, H. Fang, X. Zheng and T. Yashima, Int. J. Hydrogen Energy, 2006, 31, 555-561. 
10 M. C. J. Bradford and M. A. Vannice, Catal. Rev.: Sci. Eng., 1999, 41, 1-42.

11 D. Pakhare and J. Spivey, Chem. Soc. Rev., 2014, 43, 7813-7837.

12 L. Karam and N. El Hassan, J. Environ. Chem. Eng., 2018, 6, 4289-4297.

13 S. Damyanova, B. Pawelec, K. Arishtirova, J. L. G. Fierro, C. Sener and T. Dogu, Appl. Catal., B, 2009, 92, 250-261.

14 J. Horlyck, C. Lawrey, E. C. Lovell, R. Amal and J. Scott, Chem. Eng. J., 2018, 352, 572-580.

15 R. Zhang, G. Xia, M. Li, Y. Wu, H. Nie and D. Li, J. Fuel Chem. Technol., 2015, 43, 1359-1365.

16 S. E. Evans, J. Z. Staniforth, R. J. Darton and R. M. Ormerod, Green Chem., 2014, 16, 4587-4594.

17 W. J. Jang, H. M. Kim, J. O. Shim, S. Y. Yoo, K. W. Jeon, H. S. Na, Y. L. Lee, D. W. Jeong, J. W. Bae, I. W. Nah and H. S. Roh, Green Chem., 2018, 20, 1621-1633.

18 K. Tao, L. Shi, Q. Ma, D. wang, C. Zeng, C. Kong, M. Wu, L. Chen, S. Zhou, Y. Hu and N. Tsubaki, Chem. Eng. J., 2013, 221, 25-31.

19 X. Lv, J. Chen, Y. Tan and Y. Zhang, Catal. Commun., 2012, 20, 6-11.

20 L. Karam, S. Casale, H. El Zakhem and N. El Hassan, J. CO2 Util., 2017, 17, 119-124.

21 Y. Zhao, Y. Kang, H. Li and H. Li, Green Chem., 2018, 20, 2781-2787.

22 M. N. Kaydouh, N. El Hassan, A. Davidson, S. Casale, H. El Zakhem and P. Massiani, C. R. Chim., 2015, 18, 293-301.

23 M. N. Kaydouh, N. El Hassan, A. Davidson, S. Casale, H. El Zakhem and P. Massiani, Microporous Mesoporous Mater., 2015, 220, 99-109.

24 S. Andraos, R. Abbas-Ghaleb, D. Chlala, A. Vita, C. Italiano, M. Laganà, L. Pino, M. Nakhl and S. Specchia, Int. J. Hydrogen Energy, 2019, 44, 25706-25716.

25 L. Karam, M. Armandi, S. Casale, V. El Khoury, B. Bonelli, P. Massiani and N. El Hassan, Energy Convers. Manage., 2020, 225, 113470.

26 L. Karam, J. Reboul, S. Casale, N. El Hassan and P. Massiani, ChemCatChem, 2019, 12, 373-385.
27 L. Karam, J. Reboul, N. El Hassan, J. Nelayah and P. Massiani, Molecules, 2019, 24, 4107-4120.

28 H. Konnerth, B. M. Matsagar, S. S. Chen, M. H. G. Prechtl, F. K. Shieh and K. C. W. Wu, Coord. Chem. Rev., 2020, 416, 213319.

29 A. Saffer and R. S. Barker, US Pat., 2833816, 1958.

30 E. S. M. El-Sayed and D. Yuan, Green Chem., 2020, 22, 4082-4104.

31 T. S. Gomes, L. L. Y. Visconte and E. B. A. V. Pacheco, J. Polym. Environ., 2019, 27, 533-548.

32 A. B. Raheem, Z. Z. Noor, A. Hassan, M. K. Abd Hamid, S. A. Samsudin and A. H. Sabeen, J. Cleaner Prod., 2019, 225, 1052-1064.

33 R. Meys, F. Frick, S. Westhues, A. Sternberg, J. Klankermayer and A. Bardow, Resour., Conserv. Recycl., 2020, 162, 105010.

34 G. Lonca, P. Lesage, G. Majeau-Bettez, S. Bernard and M. Margni, Resour., Conserv. Recycl., 2020, 162, 105013.

35 S. Manju, P. K. Roy, A. Ramanan and C. Rajagopal, Mater. Lett., 2013, 106, 390-392.

36 T. Loiseau, C. Serre, C. Huguenard, G. Fink, F. Taulelle, M. Henry, T. Bataille and G. Férey, Chem. - Eur. J., 2004, 10, 1373-1382.

37 A. Wolf, A. Jess and C. Kem, Chem. Eng. Technol., 2016, 298, 1040-1048.

38 G. Kolb, T. Baier, J. Schürer, D. Tiemann, A. Ziogas, S. Specchia, C. Galletti, G. Germani and Y. Schuurman, Chem. Eng. J., 2008, 138, 474-489.

39 L. D. Vella and S. Specchia, Catal. Today, 2011, 176, 340-346.

40 J. W. Han, J. S. Park, M. S. Choi and H. Lee, Appl. Catal., B, 2017, 203, 625-632.

41 S. Tang, L. Ji, J. Lin, H. C. Zeng, K. L. Tan and K. Li, J. Catal., 2000, 194, 424-430.

42 D. Chen, K. O. Christensen, E. Ochoa-Fernández, Z. Yu, B. Tøtdal, N. Latorre, A. Monzón and A. Holmen, J. Catal., 2005, 229, 82-96.

43 M. Trueba and S. P. Trasatti, Eur. J. Inorg. Chem., 2005, 3393-3403.

44 D. Shen, M. Huo, L. Li, S. Lyu, J. Wang, X. Wang, Y. Zhang and J. Li, Catal. Sci. Technol., 2020, 10, 510-516. 